\title{
The Journey Starts Here: Finding special education research in subscription databases
}

Christina C. Wray, Assistant Librarian

ccwray@indiana.edu

Center for Disability Information and Referral, Indiana Institute on Disability and Community 2853 E. $10^{\text {th }}$ St.

Indiana University, Bloomington, IN 47408

\begin{abstract}
When providing reference services to students in multidisciplinary or emerging fields it can be especially challenging to identify which subscription databases offer the best access to relevant materials. By using citation analysis methods to create a balanced checklist, not only can librarians identify prominent resources in the field, but also have a better understanding of which disciplines are contributing to the field. This study looked at Special Education and identified 39 journals from five disciplines that were highly cited across disciplines and found that EBSCO's Academic Search Premier provided the best access to the materials.
\end{abstract}

Keywords: "special education" "database evaluation" "checklist evaluation" "multidisciplinary fields" "reference services"

Introduction

Writing your first academic research paper is challenging, and for many students it's also their first introduction to library resources. It's easy to understand why students turn to Google or Wikipedia to begin their searching. They provide interfaces students are comfortable with and access to information in ways that students understand. Librarians encourage undergraduates to begin their research in a library-provided subscription database. Students uncomfortable with the idea of writing a research paper may be hard to convince that library resources are the best place to start. It's important for students to have a positive experience with this process. The best way to ensure this is to provide them with access to a database that has a high probability of containing materials they need. For many 
students, the first place to start looking for research materials is a specialized database that indexes the academic writings of their discipline. But what if they are working in a multidisciplinary field such as special education? Will they always get the best results in a subject specific database? Which of the subject databases will offer the best coverage? This study will attempt to answer three questions: 1) What are the core journals for special education, 2) Which disciplines contribute to the field of special education, and 3) Which database offers the most access to these titles?

\section{Literature Review}

In the Dictionary for Library and Information Science compiled by Joan Rietz, a core list is defined as: "A list of the best books, periodicals, etc. on a subject or in a discipline" $(2004,184)$. Unfortunately, how to go about creating one is not as clearly defined. In his article "Journals in the Core Collection," Thomas E. Nisonger identifies ten methods that can be used to develop a core list. One of these is to utilize citation analysis to identify the core list of materials in a subject or discipline (2007). In this study, citation data was used in two different ways to create a balanced core list for an undergraduate audience in the multidisciplinary area of Special Education: a tiered checklist and citation counts.

A tiered checklist is created by comparing multiple sources, then creating a new list of ranked resources. Ranking is based on the number of sources in which the identified resource appears (Dennision 2000). For example, if three lists of "best books of 2010 " were compared, and twelve of the books appeared on all three lists, those twelve books would be considered the "core" books of 2010. The books that only appeared on two of the lists would be considered "recommended" books of 2010, and those that appeared only on one list would be thought of as "comprehensive." These terms are taken from a collection development perspective, so core items are essential to the collection, recommended items are considered very important but not essential and comprehensive items are only necessary if a very thorough collection in this area is desired. When looking at a multidisciplinary field, 
this method identifies which resources are cited widely across the disciplines that contribute to the field. This information is essential to providing comprehensive reference services for researchers working in a multidisciplinary field.

Citation counts also use multiple sources to create a ranked list of resources, but in this method it doesn't matter how many sources identify the resource. This method focuses instead on how many times the resource is cited in all the sources. So the resource that is cited the most is viewed as most important, even if those citations only come from two of the sources. Like the tiered checklist method, the resulting list is divided into the three categories of core, recommended and comprehensive.

In this study the goal is to identify which journals are "core" to the field of special education. To do this, a data set of citations will be needed. To create this data set, referenced citations will be gathered from articles published in five special education journals published in 2008. It's important to choose representative journals to limit bias in the final list (4; Schloman 1997; Black 2001; Crawley-Low 2006; Dennison 2000). Along with bias, other potential problems to be aware of are the arbitrary nature of creating the cut off points for deciding what is considered core(9) and the lack of consistent outcomes between studies (Corby 2003). Core lists, by definition, are not able to provide a universal list for a specific subject that will fit every need. The ability to mitigate the impact of the problems associated with core lists comes from choosing the best methods and sources to fit the need of a specific project. By using citation analysis, it was possible to identify which journals are most broadly used in the discipline (tiered checklist method) and which were most frequently used (citation count method). Citation analysis also identifies which core subjects contribute to the discipline. This knowledge allows reference librarians and educators to better guide undergraduates and new scholars in the research process. 
The use of electronic journals has surpassed that of print journals, particularly in the social sciences (Tenopir and King 2009; Sutton and Jocoby 2008). Therefore it is especially important to have an idea of which databases offer the best coverage for specific populations that are served by the library. Using a checklist is a well-established method to identify which database offers the most access to a discipline. Typically, checklists designed to evaluate database coverage are comprised of either Journal Titles (Ingold 2007; Schroeder 2008; Sutton and Foulke 1999) or citations (Nisonger 2008; Walters 2007; Speare 2010). For this study it was decided to use a list of core journal titles that were broadly and heavily cited. This decision was made because, as in Sutton and Foulke's study, the goal of this study is to determine which database provides the best access to the core journals of a multidisciplinary field (19) as opposed to the most influential or core articles in a field (20).

Most of the literature on database evaluation framed the discussion as a collection management problem. Database evaluation can also be helpful in shaping the way librarians promote and instruct patrons in their quest to find information. It is particularly important in multidisciplinary fields to look beyond database descriptions when searching for the best fit when guiding students new to the research process.

\section{Methodology}

The first phase of this evaluation was to identify a list of core journals in the field of special education (see Appendix A). The intended use of this core journal list is to act as a checklist to determine which electronic database offers the best access for undergraduates looking for research in the field of special education. Two approaches were used to analyze the data set:

- a tiered checklist was created to identify the journals that are used by researchers across the disciplines 
- a citation count checklist was created by analyzing reference counts to create a list that identified the most highly cited journals in the data set

The tiered checklist ensures that the journals which publish articles that are cited by researchers from all of the disciplines are represented, while the citation count checklist identifies the journals most heavily cited. Neither checklist alone is sufficient to identify the journals that would be most essential for scholars just starting out in the field of special education. This population needs access to journals which are both cited by scholars across the disciplines and are cited often. To ensure that each journal on the final checklist met both of these criteria a third checklist, referred to as a "balanced checklist," was created by identifying the titles thought to be core titles on both lists. This third checklist, then, will act as the checklist used when assessing databases.

To begin developing the checklists, a data set of cited journal titles was needed. The published articles from 2008 of five special education journals were chosen to act as the source set of journals to collect citations from: Research in Developmental Disabilities, American Journal on Mental Retardation (now known as the American Journal on Intellectual \& Developmental Disabilities), Exceptional Children, Journal of Special Education and Journal of Intellectual Disability Research. In an effort to keep the list unbiased toward a specific discipline two of the source journals are education journals, two are medical journals and one of the journals is a social sciences journal as defined by their Library of Congress subject classification listed in Ulrich's Periodical Directory. These journals all have generalized content and are ranked in the top 10 special education journals based on their impact of the field of special education as defined by the Journal Citation Report.

Next, the cited references from the 216 articles published in 2008 in the source set were collected. Because the study focused on journals, all citations for books or unpublished works were discarded. Then, for the remaining 6691 references, the title of the journal in which the reference was 
published was entered in an Excel file to create the data set that would be used to identify the core journals. The cited journal title names were manually examined in order to standardize journal titles and combine previous and current journal titles in instances when journals had changed their names.

Citation counts were combined under the most recent title name as of 2008 . If the name of the journal has changed since 2008 the current title was noted as well. For each journal title it was noted:

- Which journal(s) in the source set cited the journal title

- the number of times the journal title was cited in each source journal

- for the titles categorized as "core" journals, the Library of Congress Subject category listed in Ulrich's Periodical Directory

This process took approximately $10 \mathrm{hrs}$. It was made significantly easier when the source journal was indexed by a database that allowed the references cited from each article to be exported to Endnote automatically.

\section{Tiered Checklist}

A tiered checklist was developed from the data set by looking at how many of the source set of journals cited the journal title at least once. The journal titles were then divided into the following categories or tiers:

- Core titles: Journal titles that were referenced in four or five of the source journals

- Recommended titles: Journal titles that were referenced in two or three of the source journals

- Comprehensive titles: Journal titles that were referenced in only one of the source journals

\section{Citation Counts}


A second checklist was developed from the data set by looking at the total number of citations for each journal title combined from all five source journals. The journal titles were then divided into three categories based on citation counts:

- Core journals: Journal titles which were referenced at least twenty times

- Recommended journals: Journal titles which were referenced five times or more, but less than twenty times

- Comprehensive journals: Journal titles which are referenced less than five times

Titles which are considered core titles would be essential for undergraduates because they are the most frequently cited journal titles in the field. Titles considered recommended and comprehensive would be appealing to researchers in the field and advanced students.

Because this study is intended to identify which electronic database is the best place to start for undergraduates studying special education, it is most important to identify journals which are both frequently cited as well as used by researchers across the disciplines that make up the field of special education. To achieve this, a balanced checklist (see appendix A) was created that only included titles which were categorized as core titles on both lists. This resulted in a refined list targeted to the information needs of the intended population.

\section{Database Coverage}

Four databases were evaluated to gauge which one would provide the best full text and indexing access to the journals on the balanced checklist. The databases were chosen based on three main criteria: undergraduates are considered a target audience, they provide at least some full text access, and they cover a subject relevant to special education. The following databases were evaluated in this study: one general database (Academic Search Premier); one Education database (Education Full Text); one Medical Database (CINAHL with Full Text) and one Psychology database (EBSCO Psychology \& 
Behavioral Sciences Collection). For each database, the title list provided by the database vendor was checked against the balanced checklist. For each journal title it was noted:

- If the title was indexed by the database

- If there was any full text availability for the title.

\section{Results:}

\section{Balanced Core List}

After journal titles were combined to reflect the most current title in 2008 , the source data provided 1,149 journal titles. Thirty-nine titles appear on both core lists; these journal titles make up the "balanced core" journal list which was used to evaluate database coverage. This list can be found in Appendix A. As illustrated in Figure 1, of the journal titles categorized as balanced core journals; fifteen (38 percent) were medical journals, eleven (28 percent) were education journals, seven (18 percent) were psychology journals, five (13 percent) were social science journals, and one ( 3 percent) was a science journal.

Figure 1: Disciplines contributing to the field of special education

Figure 1: Disciplines contributing to the balanced core list of journals

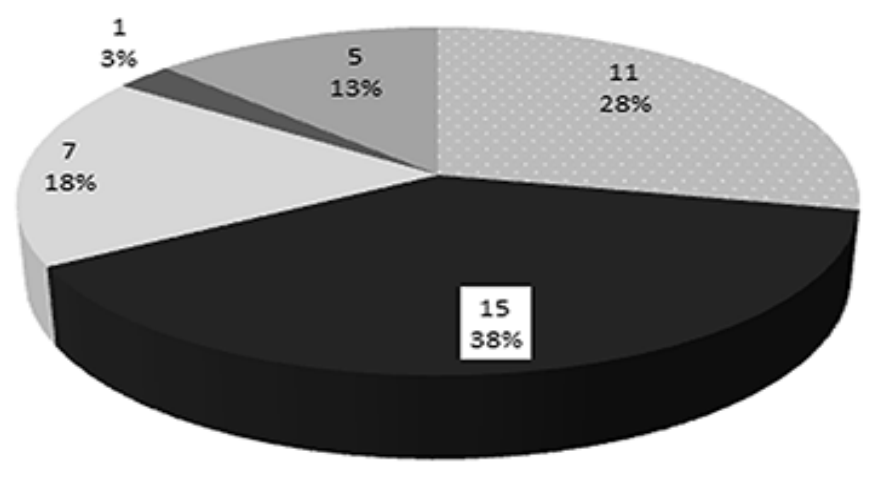

$$
\begin{aligned}
& \text { = Education } \\
& \text { - Medical } \\
& \text { = Psychology } \\
& \text { = Science } \\
& \text { = Social Science }
\end{aligned}
$$




\section{Database Coverage}

Academic Search Premier (EBSCO) provided access to thirty-four (87 percent) of the titles on the balanced core journal list. Twenty (58 percent) of the titles had some full text availability. Eighty-two percent of the Education titles, 87 percent of the Medical titles, 100 percent of the Psychology titles, the Science title and 80 percent of the Social Science titles are indexed. Of the titles indexed, 57 percent have some full text availability.

Education Full Text (WilsonWeb) provided access to twenty-eight (72 percent) of the titles on the balanced core journal list. Seventeen (44 percent) of the titles had some full text availability. Ninety-one percent of the education titles, 53 percent of the medical titles, 100 percent of the psychology titles and 60 percent of the social science titles are indexed. Of the titles indexed, 61 percent have some full text availability.

\section{Psychology \& Behavioral Sciences Collection (EBSCO) provided access to seventeen (44 percent)} of the titles on the balanced core journal list. Seventeen (44 percent) of the titles had some full text availability. Fifty-four percent of the education titles, 53 percent of the medical titles, 14 percent of the psychology titles, the science title and 20 percent of the social science titles are indexed. Of the titles indexed, 100 percent have some full text availability.

CINAHL with Full Text (EBSCO) provided access to nine (23 percent) of the titles on the balanced core journal list. Six (15 percent) of the titles had some full text availability. Nine percent of the education titles, 33 percent of the medical titles and 42 percent of the psychology titles are indexed. Of the titles indexed, 67 percent have some full text availability. 


\section{Discussion:}

\section{Core List}

Both the tiered checklist method and the citation count method have inherent weaknesses.

Tiered lists do not take into consideration the number of times a title is referenced in each source journal. A given title may have only appeared once in each of the five journals, yet it still qualifies as a "core" title in the tiered method, while a journal that was referenced 50 times, but only by three of the five source journals will not. Tiered checklists can also be misleading in a multidisciplinary field like Special Education when specific journals may be more focused on one discipline than another, resulting in publishing articles that may not cite journals outside of that subject. For instance, medical journals may not cite education journals, thus making it less likely that an education journal will appear in all five source journals.

On the other hand, citation counts can be influenced by "hot topic" articles that may inflate the number of citations for a journal as well as self-citing. Self-citing is defined as citations of articles published in the same journal as the citation. For example if an article is published in Exceptional Children and it cites other articles published in Exceptional Children, those citations are known as selfcitations. Citation counts are also more heavily weighted towards disciplines which cite more frequently. Forty-four percent of the core journal titles on the citation counts checklist were medical journals compared to only 32 percent of the core journal titles on the tiered checklist.

Both checklists are influenced by the source set. Potential bias was minimized by choosing source journals from a variety of disciplines that cover broad topics and have a high impact on the field according to the Journal Citation Report. There are a host of problems with JCR ranking, mainly that they are very US centric and do not represent an accurate picture of the ranked fields because of that. In the area of Education there is a secondary problem associated with using JCR ranking as a selecting tool in 
that the research focus of the Institute of Scientific Information (ISI) excludes the more practice-based journals that are so important to the field (21). For this evaluation, these problems were seen to be limited because undergraduates at U.S. colleges and universities were the intended beneficiaries of the final checklist, and the practical journals would be cited in the research journals as well thus the most influential practical journals would be represented. The inherent weaknesses were also undermined in the final core list by including only those that are considered core journals by both checklists. This combined approach resulted in a list of 39 core journals in the field of special education (see Appendix A).

A combined method was chosen for this evaluation because the end result of the project was to help identify the best place for undergraduates who are looking for general research in the area of special education to begin their searches. The journals that appear on the balanced core list are both highly cited and referenced across the disciplines that make up the field of special education. Therefore, it is likely that having access to the journal is beneficial. The balanced core list identified that the bulk of citations originate from medical and education journals, followed by psychology and social science journals.

For a more conclusive look at the makeup of disciplines influencing special education it would be necessary to analyze citations from a longer period of time and a wider set of source materials. This type of research would help librarians and researchers better understand the field of special education and ensure that students and researchers have access to materials from all disciplines that influence the field.

\section{Database Evaluation}

One of the most important criteria for judging which database is the best starting place for special education researchers was how accessible the balanced core list was to users of the database. 
Figure 2 provides a side by side comparison of the four databases evaluated. Academic Search Premier provided the best access to the balanced core list. It offers current indexing for thirty-three of the thirty-four titles it indexes and current full text access for thirteen of the twenty journals to which it provides access. It also offers the best variety of subject coverage across the four disciplines as you can see in Figure 3. Education Full Text offers access to three journals not covered by Academic Search Premier: American Journal on Mental Retardation, Behavioral Disorders and Education and Training in Developmental Disabilities. This results in Education Full Text providing slightly better access in the area of Education and the Social Sciences.

Figure 2: percentage for each type of access of balanced core list titles by database

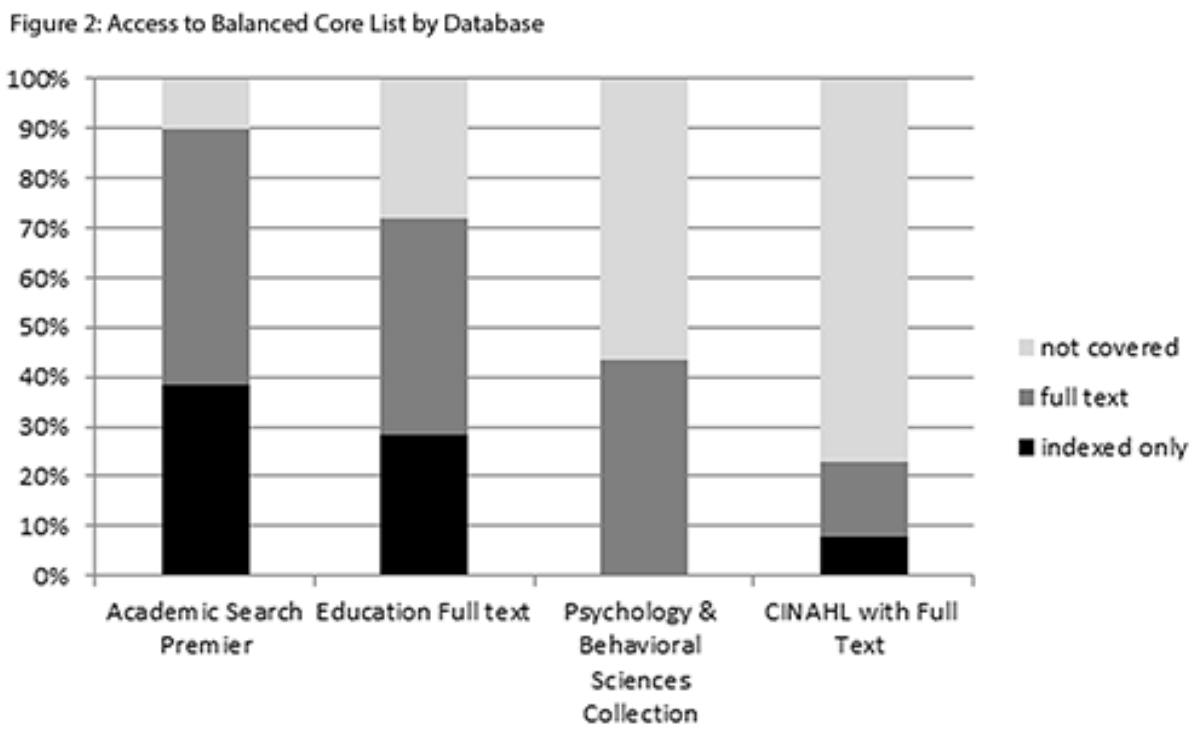


Figure 3: percentage of coverage for each discipline in each database

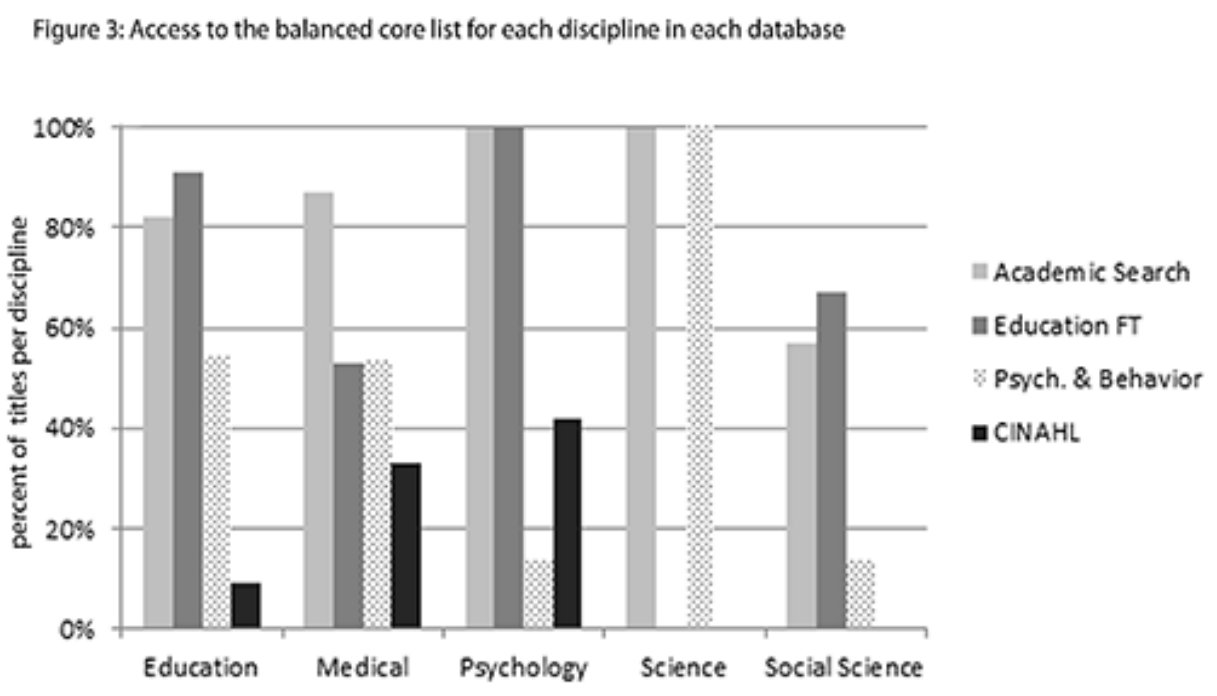

Between Academic Search Premier and Education Full Text, access to all but two journal titles on the balanced core list was provided. Of the remaining two titles, Archive of General Psychology was not covered in any of the four databases, and the Journal of Early Intervention was only indexed in CINAHL with Full Text after 2005. Academic Search Premier, especially when coupled with a link resolving service that allows student to view the full text availability of an article regardless of which subscription database makes it available, would meet most undergraduate special education majors' needs.

An in-depth look at the actual database indexing and full text availability compared to what is advertised as offered would be beneficial. This would require looking at not only what was stated as offered, but also gathering data on what percentage of the journal run is indexed and how it compares to the citing half-life for the subject area, that is the median age of the articles cited by researchers in this field (Journal Citation Reports 2010), and whether the coverage meets the need for current research in the field. It would also be helpful to evaluate further criteria other than just accessibility. 
Usability and search precision are also very important, particularly for an undergraduate audience who are just being introduced to academic databases and the role they play in performing academic research.

\section{Conclusion:}

Using the criteria of journals that are highly cited across the main disciplines that make up special education, a balanced checklist was created. It was found that the disciplines of medicine, education, social sciences and psychology were highly represented in special education research; thirtynine journals were identified as being core to special education (see Appendix A). The resulting balanced checklist was used to determine which database of the three subject databases and one multidisciplinary database evaluated provided the most access to the journal titles on the balanced checklist. It was found that EBSCO's Academic Search Premier provided the most indexing and full text access to the journals essential for undergraduates researching in the area of special education, as defined by the method employed in this study.

The methods employed in this study are relatively quick and easy to do and are a good way to get a broad view of multidisciplinary and emerging fields. Looking outside of traditional reference service evaluations to other specializations within library and information science can help librarians provide better, more personalized services to our patrons. In ten to fifteen hours, reference librarians can have a general landscape of a field of study and a clear idea of which database offers the best access for the needs of a specific population tailored to their library's available resources. This can be an especially helpful study for new librarians or librarians new to a position or subject area to conduct. By gathering this type of information, it can help inform them of the resources frequently used by researchers in a field as well as which disciplines contribute to their subject area. 


\section{Appendix A - Core Journals in Special Education}

American Journal on Mental Retardation (American Journal on Intellectual \& Developmental Disabilities) American Psychologist

Archives of General Psychiatry

Behavior Modification

Behavioral Disorders

Child Development

Developmental Psychology

Education \& Training in Developmental Disabilities

Education \& Treatment of Children

European Child \& Adolescent Psychiatry

Exceptional Children

Journal of Abnormal Child Psychology

Journal of Abnormal Psychology

Journal of Applied Behavior Analysis

Journal of Autism \& Developmental Disorders

Journal of Child Psychology \& Psychiatry

Journal of Clinical Child \& Adolescent Psychology

Journal of Consulting \& Clinical Psychology

Journal of Developmental \& Physical Disabilities

Journal of Early Intervention

Journal of Educational Psychology

Journal of Emotional \& Behavioral Disorders

Journal of Intellectual Disability Research

Journal of Learning Disabilities

Journal of Personality \& Social Psychology

Journal of Positive Behavior Interventions

Journal of Special Education

Journal of Speech Language \& Hearing Research

Journal of the American Academy of Child \& Adolescent Psychiatry

Mental Retardation (Intellectual \& Developmental Disabilities)

Mental Retardation \& Developmental Disabilities Research Reviews

Nature

Pediatrics

Psychological Bulletin

Remedial \& Special Education

Research \& Practice for Persons with Severe Disabilities

Research in Developmental Disabilities

Review of Educational Research

School Psychology Review 


\section{Works Cited}

1. Rietz, Joan M. 2004. Dictionary for Library and Information Science. Westport, CT: Libraries Unlimited.

2. Nisonger, Thomas E. "Journals in the core collection," The Serials Librarian 51 no. 3: 51-73. doi: 10.1300/J123v51n03_05

3. Dennison, RF. "Quality Assessment of Collection Development through Tiered Checklists: Can You Prove You Are a Good Collection Developer?" Collection Building 19, no. 1 (2000): 24-26 doi:10.1108/01604950010310866

4. Nisonger, "Journals in the Core," 57.

5. Schloman, BF. "Mapping the Literature of Allied Health: Project Overview." Bulletin of the Medical Library Association 85, no. 3 (1997): 271.

6. Black, Steven. "Using Citation Analysis to Pursue a Core Collection of Journals for Communication Disorders." Library resources \& technical services 45, no. 1 (2001): 3-9

7. Crawley-Low, J. "Bibliometric Analysis of the American Journal of Veterinary Research to Produce a List of Core Veterinary Medicine Journals." Journal of the Medical Library Association 94, no. 4 (2006): 430-434.

8. Dennison, RF. "Quality Assessment of Collection Development through Tiered Checklists

9. Nisonger, "Journals in the Core," 66.

10. Corby, Katherine. "Constructing Core Journal Lists: Mixing Science and Alchemy." portal: Libraries and the academy 3, no. 2 (2003): 207-17.

11. Tenopir, Carol, and Donald W. King. "Electronic Journals and Changes in Scholarly Article Seeking and Reading Patterns." Aslib Proceedings 61, no. 1 (2009): 5-32.

12. Sutton, Allison M., and JoAnn Jacoby. "A Comparative Study of Book and Journal Use in Four Social Science Disciplines." Behavioral \& Social Sciences Librarian 27, no. 1 (2008): 1-33. 
13. Ingold, Cindy. "Women's Studies Databases: A Critical Comparison of Three Databases for Core Journals in Women and Gender Studies." Library Trends 56, no. 2 (2007): 449-68.

14. Schroeder, Judy. "An Overlap Analysis of Occupational Therapy Electronic Journals Available in Full-text Databases and Subscription Services." Journal of Electronic Resources in Medical Libraries 5 no. 4 (2008): 346-361.

15. Sutton, Ellen, and Lori Foulke. "Coverage of Anthropology by Major Electronic Indexes: A Comparison." Reference Services Review 27, no. 2 (1999): 134-57.

16. Nisonger, Thomas E. "Use of the Checklist Method for Content Evaluation of Full-Text Databases: An Investigation of Two Databases Based on Citations from Two Journals." Library Resources \& Technical Services 52, no. 1 (2008): 4-17.

17. Walters, William H. "Google Scholar Coverage of a Multidisciplinary Field." Information Processing \& Management 43 (2007): 1121-1132.

18. Speare, Marie. "Environmental Microbiology: A Database Coverage Study." Science \& Technology Libraries 29 no. 1 (2010): 1-15.

19. Sutton, Ellen, and Lori Foulke. "Coverage of Anthropology, " 134.

20. Walters, William H. "Google Scholar Coverage" 1124.

21. Corby, Katherine. "Constructing Core Journal Lists" pp. 210-211.

22. Journal Citation Reports. 2010. Citing half-life. http://adminapps.isiknowledge.com/ JCR/help/h_ctghl.htm\#aggctghl 